\title{
Effects of permanent dual chamber pacing on myocardial perfusion in symptomatic hypertrophic cardiomyopathy
}

\author{
J L Posma, P K Blanksma, E E Van Der Wall, W Vaalburg, H J G M Crijns, K I Lie
}

\begin{abstract}
Objective-Angina and the presence of myocardial ischaemia are common in hypertrophic cardiomyopathy. Dual chamber pacing results in clinical improvement in these patients. This study evaluates the effects of permanent dual chamber pacing on absolute regional myocardial perfusion and perfusion reserve.

Setting-University hospital.

Patients and design-Six patients with hypertrophic cardiomyopathy and severe symptoms of angina received a dual chamber pacemaker. Absolute myocardial regional perfusion and perfusion reserve (dipyridamole $0.56 \mathrm{mg} / \mathrm{kg}$ ) were measured by dynamic positron emission tomography with ${ }^{13} \mathrm{~N}$-ammonia both during sinus rhythm and 3 months after pacemaker insertion. Results were compared with those from 28 healthy volunteers.
\end{abstract}

Results-Pacing resulted in a reduction of anginal complaints and a reduction in intraventricular pressure gradient from 65 (SD 30) $\mathrm{mm} \mathrm{Hg}$ to 19 (10) $\mathrm{mm} \mathrm{Hg}$. During sinus rhythm, baseline perfusion was higher in patients with hypertrophic cardiomyopathy than controls (184 (31) $v$ $106(26) \mathrm{ml} / \mathrm{min} / 100 \mathrm{~g}, P<0.01)$, and perfusion reserve was lower $(1.6(0.4)$ v 2.8 $(1 \cdot 0), P<0 \cdot 05)$. During pacing myocardial perfusion decreased to 130 (27) $\mathrm{ml} / \mathrm{min} / 100 \mathrm{~g} \quad(P<0.05)$, with variable responses in terms of perfusion reserve. Pacing caused a redistribution of myocardial stress perfusion and perfusion reserve. The coefficient of regional variation of myocardial stress perfusion decreased from $19 \cdot 7(7 \cdot 0) \%$ to $14.6(3.9) \%$ during pacing $(12.9(3.8) \%$ in controls, $P<0.01)$. The coefficient of regional variation of perfusion reserve decreased from $16.7(6.6) \%$ to $11.4(2.6) \%$ during pacing (9.8 (4.1)\% in controls, $P<0.01)$.

Conclusions-Pacing caused a decrease of resting left ventricular myocardial blood flow and blood flow during pharmacologically induced coronary vasodilatation. Although global perfusion reserve remained unchanged, myocardial perfusion reserve became more homogeneously distributed.

(Heart 1996;76:358-362)
Keywords: hypertrophic cardiomyopathy; pacing; perfusion imaging

Patients with hypertrophic cardiomyopathy typically complain of dyspnoea, angina, and presyncope and/or syncope on exertion. ${ }^{1}$ Considerable evidence points to the importance of myocardial ischaemia in patients with hypertrophic cardiomyopathy, ${ }^{2}$ especially in young patients in whom ischaemia is frequently related to sudden cardiac death. ${ }^{3}$ Myocardial ischaemia has been repeatedly demonstrated in both obstructive and nonobstructive hypertrophic cardiomyopathy by the presence of fixed and reversible thallium perfusion defects, ${ }^{3-5}$ by measurement of myocardial lactate production, particularly during rapid atrial pacing, ${ }^{67}$ and by positron emission tomography (PET). ${ }^{8-13}$

Permanent dual chamber (DDD) pacing improves subjective symptoms in about $80 \%$ of the patients with drug refractory obstructive hypertrophic cardiomyopathy. ${ }^{14}$ Right ventricular pacing is believed to exert its beneficial haemodynamic effects by reducing the left ventricular outflow gradient by creating abnormal septal motion. ${ }^{15}$ The mechanisms by which pacing can improve symptoms in patients with the disease remain speculative but altered myocardial metabolism is a prime candidate. $^{216}$ Exercise thallium-201 scintigraphy showed a decrease in perfusion defects during DDD pacing in several patients with hypertrophic cardiomyopathy, ${ }^{217}$ but the effects of DDD pacing on absolute myocardial blood flow and flow reserve are unknown. Therefore, we studied myocardial perfusion in a group of six patients with hypertrophic cardiomyopathy by means of nitrogen-13 ammonia and PET before and during permanent DDD pacing.

\section{Patients and methods}

PATIENTS

The baseline characteristics of the six patients are described in table 1 . In each patient, the diagnosis of hypertrophic cardiomyopathy was based on cross sectional echocardiography, showing a hypertrophied, non-dilated left ventricle in the absence of identifiable cardiac or systemic stimuli to hypertrophy. ${ }^{18}$ All had severe symptoms of chest pain despite the use of adequate doses of calcium entry blockers and/or a $\beta$-blocking agent. The patients were symptomatic at rest or on minimal exercise. All patients had disproportionate thickening of 
Table 1 Baseline characteristics of the six study patients with hypertrophic cardiomyopathy

\begin{tabular}{llllll}
\hline Caselage/sex & NYHA FC & Symptoms & Prior medications & $\begin{array}{l}\text { Septallateral } \\
\text { wall thickness (mm) }\end{array}$ & $\begin{array}{l}\text { LVOT gradient (mm Hg) } \\
\text { SR/pacing }\end{array}$ \\
\hline $155 / \mathrm{M}$ & IV & AP, FA & Verapamil & $23 / 11$ & $10 / 6$ \\
$257 / \mathrm{M}$ & IV & AP, D & Verapamil, metoprolol, & $35 / 12$ & $66 / 15$ \\
& & amiodarone & & $88 / 37$ \\
$437 / \mathrm{F}$ & III & AP, D & Verapamil, disopyramide & $22 / 10$ & $104 / 30$ \\
$574 / \mathrm{F}$ & IV & AP, D, FA & Verapamil, metoprolol & $23 / 20$ & $45 / 12$ \\
$639 / \mathrm{F}$ & III & AP, D, S & Diltiazem & $17 / 12$ & $77 / 17$ \\
\hline
\end{tabular}

AP, angina pectoris; D, dyspnoea; F, female; FA, fatigue; FC, functional class; LVOT, left ventricular outflow tract; M, male; NYHA, New York Heart Association; S, syncope; SR, sinus rhythm.

the ventricular septum with respect to the posterior left ventricular free wall (septal-to-free wall ratio of 1.9 to $3 \cdot 8$, mean (SD) $2.5(0.6)$. Cardiac catheterisation demonstrated significant left ventricular outflow tract obstruction with a gradient at rest of $>30 \mathrm{~mm} \mathrm{Hg}$ in five patients (mean (SD) $76(20) \mathrm{mm} \mathrm{Hg}$ ). The patient without obstruction received a pacemaker because symptomatic benefit with pacing has also been demonstrated in this patient group. ${ }^{19}{ }^{20}$ All had angiographically normal epicardial coronary arteries.

\section{PACEMAKER THERAPY}

DDD permanent pacemakers were implanted in five patients and a VDD pacemaker in one patient by standard techniques (ventricular lead at right ventricular apex). Ventricular capture was maintained at maximum exercise by programming the resting atrioventricular delay to 90 (7) $\mathrm{ms}$, and activating the rateadaptive atrioventricular interval shortening. Three months after pacemaker insertion a repeat cross sectional echocardiogram with Doppler and PET study were performed in each patient. PET data were compared with the results obtained from 28 healthy volunteers.

PET IMAGING PROTOCOL

Myocardial perfusion was studied before and after pacemaker insertion with dynamic PET, according to the methods of Schelbert et $a l^{21}$ and Bellina et $a l^{22}$ using ${ }^{13} \mathrm{~N}$-ammonia as tracer. All medication was stopped two days before the PET procedure. Subjects were positioned in an ECAT Siemens $951 / 31$ positron camera, imaging 31 planes simultaneously over $10.8 \mathrm{~cm}$. Photon attenuation was corrected using a retractable external ring source filled with ${ }^{68} \mathrm{Ge} /{ }^{68} \mathrm{Ga}$. Dynamic imaging was started at the time of ${ }^{13} \mathrm{~N}$-ammonia injection (370 MBq) and was continued for $15 \mathrm{~min}$ (frames: $12 \times 10 \mathrm{~s}, 1 \times 2 \mathrm{~min}, 1 \times 4 \mathrm{~min}$, $1 \times 7 \mathrm{~min}$ ). The resting study was followed by a stress study with dipyridamole, which was performed by injecting $0.56 \mathrm{mg}$ dipyridamole/kg body weight over four minutes. ${ }^{13} \mathrm{~N}$-ammonia was injected $2-3 \mathrm{~min}$ after the end of the dipyridamole administration.

\section{PET IMAGE ANALYSIS}

Data for each study were reoriented to short axis images using a manually drawn long axis in the left ventricle. The total myocardium was divided into nine regions, as described previously. ${ }^{23}$ For all regions time activity curves were assessed using maximum activity. In each region absolute myocardial perfusion at rest and during dipyridamole were assessed. Myocardial perfusion reserve was defined as the ratio of dipyridamole stimulated and resting perfusion. Corrections for partial volume effects, and thus for the underestimation of counts in normal walls, and for spillover from the left ventricular cavity and the surrounding tissue were based on echocardiographic measurements of regional wall thickness and wall motion in all nine segments. To compensate for the decrease in ammonia extraction with increase in flow rates a correction was applied as described earlier. ${ }^{23}$ Myocardial perfusion values were not corrected for rate-pressure product because in patients with a dynamic left ventricular outflow tract obstruction the actual intraventricular pressure at the moment of imaging is not exactly known. Myocardial perfusion and perfusion reserve were calculated as a mean value of all nine regions, and separately as a mean value for four anterior and septal regions and for four posterior and lateral regions. As a measure of heterogeneity of myocardial perfusion and perfusion reserve, the coefficient of regional variation of perfusion and perfusion reserve of the nine regions was calculated (standard deviation/mean $\times 100$ ), as described previously. ${ }^{24}$

\section{STATISTICAL ANALYSIS}

All results are expressed as mean (SD). The significance of differences was tested using non-parametric statistical analysis (Wilcoxon signed rank test for paired data and MannWhitney $U$ test for unpaired data). A P value $<0.05$ was regarded as statistically significant.

\section{Results}

In all six patients a considerable reduction (from NYHA class III/IV to II) was seen in the severity of symptoms during DDD pacing. The intraventricular pressure gradients responded with a reduction from 65 (30) $\mathrm{mm}$ $\mathrm{Hg}$ to 19 (10) $\mathrm{mm} \mathrm{Hg}$. Rate-pressure product measured at the time of PET did not change significantly during pacing, and was not significantly different in controls and patients at baseline. Table 2 summarises baseline myocardial perfusion, myocardial perfusion during dipyridamole stress, and the perfusion reserve of the patients with hypertrophic cardiomyopathy and the 28 normal volunteers. It also shows the PET results three months after pacemaker implantation. In patients with hypertrophic cardiomyopathy, baseline myocardial perfusion was higher than in normal 
Table 2 Baseline perfusion, stress perfusion, and perfusion reserve during sinus rhythm and dual chamber pacing in six patients with hypertrophic cardiomyopathy and in 28 controls

\begin{tabular}{|c|c|c|c|c|c|c|}
\hline \multirow[b]{2}{*}{ Case } & \multicolumn{2}{|c|}{ Resting perfusion $(\mathrm{ml} / \mathrm{min} / 100 \mathrm{~g})$} & \multicolumn{2}{|c|}{ Stress perfusion $(\mathrm{ml} / \mathrm{min} / 100 \mathrm{~g})$} & \multicolumn{2}{|c|}{ Perfusion reserve } \\
\hline & $S R$ & $D D D$ pacing & $S R$ & $D D D$ pacing & $S R$ & $D D D$ pacing \\
\hline $\begin{array}{l}1 \\
2 \\
3 \\
4 \\
5 \\
6 \\
\text { Mean (1SD) } \\
\text { Ant sept (1SD) } \\
\text { Post lat (1SD) } \\
\text { Controls (1SD) } \\
\text { (n=28) }\end{array}$ & $\begin{array}{l}210 \\
171 \\
209 \\
197 \\
121 \\
195 \\
184(31) \\
181(35) \\
193(32) \\
106(26)\end{array}$ & $\begin{array}{l}108 \\
106 \\
184 \\
140 \\
117 \\
125 \\
130(27) \\
133(28) \\
133(28)\end{array}$ & $\begin{array}{l}326 \\
268 \\
300 \\
225 \\
297 \\
321 \\
289(34) \\
250(46) \\
338(33) \\
283(35)\end{array}$ & $\begin{array}{l}172 \\
219 \\
221 \\
237 \\
197 \\
242 \\
215(24) \\
199(19) \\
238(34)\end{array}$ & $\begin{array}{l}1.58 \\
1.57 \\
1.44 \\
1.13 \\
2.46 \\
1.66 \\
1.6(0.4) \\
1.4(0.4) \\
1.8(0.4) \\
2.8(0.3)\end{array}$ & $\begin{array}{l}1.60 \\
2.06 \\
1.20 \\
1.70 \\
1.70 \\
1.94 \\
1.7(0.3) \\
1.5(0.2) \\
1.8(0.3)\end{array}$ \\
\hline
\end{tabular}

Ant sept, anterior and septal regions; DDD pacing, dual chamber pacing; post lat, posterior and lateral regions; SR, sinus rhythm.

volunteers $(\mathrm{P}<0.01)$, but during dipyridamole stress myocardial perfusion was not statistically different from the corresponding values in the normal volunteers. This results in an impaired perfusion reserve in patients with hypertrophic cardiomyopathy $(1.6(0.4) v 2.8$ $(1.0)$ in controls, $P<0.05)$. During pacing a decrease in resting and stress myocardial perfusion was seen in all six patients when compared with baseline measurements $(P<0.05)$ together with an increase in perfusion reserve in four patients. Both during sinus rhythm and DDD pacing the posterolateral segments showed more myocardial perfusion during dipyridamole stress than the anteroseptal segments $(P<0.05)$, resulting in a higher perfusion reserve in the posterolateral wall. During sinus rhythm, stress perfusion and perfusion reserve were less evenly distributed in hypertrophic cardiomyopathy than in the controls; the coefficient of regional variation of stress perfusion was $19.7(7.0) \% v 12.9(3.8) \%(\mathrm{P}<$ 0.01 ), and the coefficient of regional variation of perfusion reserve was $16.7(6.6) \% \quad v \quad 9.8$ (4.1)\% $(\mathrm{P}<0 \cdot 01)$. During DDD pacing the regional distribution of stress perfusion and perfusion reserve became almost normal in patients with hypertrophic cardiomyopathy; the coefficient of regional variation was 14.6 (3.9)\% for stress perfusion, and $11.4(2 \cdot 6) \%$ for perfusion reserve. The posterolateral/ anteroseptal wall flow ratio during pharmacological stress decreased from $1.39(0.25)$ to $1 \cdot 19(0 \cdot 11)$ during DDD pacing.

\section{Discussion}

Speculation about the mechanism of benefit of DDD pacing in patients with hypertrophic cardiomyopathy has focused on left ventricular outflow tract obstruction and its reduction with pacing. Less attention has been paid to the effects of pacing on myocardial metabolism. Recent animal studies have demonstrated that pacing causes segmental differences in contractile work and induces a decrease of myocardial oxygen consumption in early activated regions. ${ }^{25-27}$ The pattern of ventricular activation during right ventricular pacing mimics that of left bundle branch block. This condition is known to be associated with a decrease in septal myocardial perfusion. So in patients with hypertrophic cardiomyopathy pacing might influence myocardial perfusion not only by a reduction in outflow gradient, and thus global oxygen demand, but also by direct effects of the altered activation pattern on local myocardial oxygen demand that are not specific to this disease.

We found that myocardial perfusion at baseline was higher than in normal controls. At variance with our findings, Camici et $a l^{10}$ did not find differences in blood flow between 23 patients with hypertrophic cardiomyopathy and 12 control subjects using the same PET method as we did. However, in their study only nine of the 23 patients reported a history of typical chest pain, and only one of these patients showed systolic anterior motion of the mitral valve that is usually seen in patients with obstruction of the left ventricular outflow tract. In the nine patients with typical angina they did indeed find a higher baseline regional myocardial blood flow both in the septum and in the free wall. ${ }^{10}$ In our study group all patients had severe angina, and five had significant outflow tract obstruction. Using great cardiac vein flow measurements Cannon et $a l^{28}$ showed that myocardial oxygen consumption and coronary blood flow were significantly higher in patients with obstruction than in those without. So the differences in baseline clinical characteristics may explain the differences in baseline flow between our results and those of Camici et al. ${ }^{10}$

During sinus rhythm we found that coronary vasodilator reserve was lower in all six patients with hypertrophic cardiomyopathy than in the controls. This difference appears to be related to a higher baseline flow rather than to a reduction in maximal flow. The finding of impaired flow reserve in hypertrophic cardiomyopathy accords with the previously reported study of Camici et $a l,{ }^{10}$ with the study of Koga et $a^{29}$ using split-dose thalliumdipyridamole scintigraphy, and with results on coronary flow dynamics and reserve assessed by transoesophageal echocardiography reported by Memmola et al. ${ }^{30}$ The exact cause of the decreased vasodilator capacity is not known and may be related to regional abnormalities or small vessel disease. ${ }^{6}$ Furthermore, impaired relaxation of the myocardium during the isovolumic and rapid filling periods could impair coronary filling. ${ }^{1}$ On the other hand, myocardial ischaemia might affect relaxation, causing a vicious cycle of diminished perfusion and impaired relaxation. In patients with 
obstructive hypertrophic cardiomyopathy other possible explanations for impaired coronary flow delivery are a greater dependence of myocardial perfusion on diastole because of systolic vascular compression with prolonged systolic ejection time, and lower coronary perfusion pressure secondary to the subcoronary obstruction. ${ }^{28}$

The effects of different treatment strategies in patients with hypertrophic cardiomyopathy on myocardial perfusion have been investigated in only a few studies. ${ }^{4132}$ Cannon et al, ${ }^{4}$ using thallium-201 scintigraphy, assessed the impact of surgical relief of left ventricular outflow obstruction on myocardial perfusion abnormalities in 20 patients with symptomatic obstructive hypertrophic cardiomyopathy. In patients with the greatest reduction in rest outflow gradient they found partial or complete normalisation of myocardial perfusion abnormalities on the images six months after the operation. Fine et $a l^{17}$ described a patient in whom a thallium-201 SPECT scintigram became normal during verapamil treatment. By contrast, Gistri et al ${ }^{32}$ could not demonstrate a change in absolute myocardial blood flow and flow reserve after verapamil treatment with PET and ${ }^{13} \mathrm{~N}$-ammonia in 20 patients. In one patient they found a redistribution of myocardial blood flow favouring the subendocardial regions after verapamil treatment. ${ }^{32}$ Two studies reported the effects of DDD pacing on thallium-201 scintigraphy in obstructive hypertrophic cardiomyopathy..$^{217}$ Fananapazir et $a l^{17}$ examined 27 patients and found perfusion defects at exercise scintigraphy in $81 \%$ of the patients. After an eight weeks of DDD pacing, the perfusion abnormalities normalised or improved in $65 \%$, but worsened in $17 \%$ of the patients. ${ }^{17}$ Recently a patient was reported in whom a dipyridamole and exercise thallium-201 image showed severe reversible defects in the septum, inferior wall, and apex. ${ }^{2}$ After a month of DDD pacing repeated thallium-201 scintigraphy showed almost completely normal images. ${ }^{2}$ These observations show that DDD pacing has a beneficial effect on ischaemia in patients with hypertrophic cardiomyopathy.

However, compared with thallium-201 scintigraphy, PET imaging offers major advantages with its potential to quantitatively study regional myocardial perfusion because of its ability to correct for attenuation. ${ }^{33}$ In patients with a global decrease or increase in myocardial perfusion a thallium scintigram would be normal. By contrast, PET imaging can provide absolute flow measurements in every desired segment of the myocardium. A previous case report was published from our institution describing a patient with non-obstructive hypertrophic cardiomyopathy studied with PET before and after pacemaker implantation. ${ }^{34}$ In that patient we found a decrease in resting perfusion during pacing without a change in perfusion reserve. This was associated with a redistribution of perfusion reserve favouring the anteroseptal segments.

Compared with that patient with nonobstructive hypertrophic cardiomyopathy, the study group presently described showed less pronounced changes in the distribution of myocardial perfusion. With pacing, there was a non-significant trend towards a more homogeneous distribution, probably caused by the same mechanism as in non-obstructive hypertrophic cardiomyopathy ${ }^{34}$; anteroseptal fibre strain and thereby oxygen demand are reduced by early activation caused by right ventricular apical pacing. ${ }^{25-27}$ However, when pacing patients with hypertrophic cardiomyopathy another major factor may be operating. Pacing in this population causes a reduction in left ventricular outflow tract obstruction and left ventricular end diastolic pressure. ${ }^{35}$ This results in a lower myocardial oxygen demand combined with an increased diastolic transcoronary perfusion gradient. Our results support this mechanism; the lower resting perfusion during DDD pacing reflects a lower oxygen demand in all parts of the left ventricle caused by a lower systolic left ventricular pressure. During pacing mean myocardial perfusion reserve remained depressed when compared with controls, but the individual responses were very varied. Perfusion reserve increased in three patients, but actually decreased in two patients during DDD pacing. This is in line with the variable results found by Fananapazir et al using thallium-201 scintigraphy. ${ }^{17} \mathrm{We}$ found no relation between the individual effect of pacing on myocardial perfusion reserve and the clinical and haemodynamic responses to pacing or baseline clinical or morphological characteristics.

It is not known why not all patients with obstructive hypertrophic cardiomyopathy respond favourably to DDD pacing with an increase in perfusion reserve and why DDD pacing causes a reduction in hyperaemic myocardial perfusion. We have only shortterm follow up on a few patients and do not know whether this possibly deleterious effect of pacing may be detrimental in the long term. Further research is necessary, especially in those patients in whom pacing induces a reduction in hypertrophy. ${ }^{35}$ In addition, it is unclear whether pacing results in ventricular dilatation and heart failure on the long run. ${ }^{15}$ At present, cautious optimism is warranted regarding pacemaker treatment in patients with obstructive hypertrophic cardiomyopathy. ${ }^{36}$ One has to wait until prospective studies are available and the effects of pacing on myocardial perfusion and other pathophysiological mechanisms are better understood.

1 Wigle ED, Rakowski H, Kimball BP, Williams WG Hypertrophic cardiomyopathy. Clinical spectrum and treatment. Circulation 1995;92:1680-92.

2 Thomson H, Fong W, Stafford W, Frenneaux M. Reversible ischaemia in hypertrophic cardiomyopathy. $\mathrm{Br}$ Heart $\mathcal{F}$ 1995;74:220-3.

3 Dilsizian V, Bonow RO, Epstein SE, Fananapazir L. Myocardial ischemia detected by thallium scintigraphy is frequently related to cardiac arrest and syncope in young patients with hypertrophic cardiomyopathy. F $\mathrm{Am} \mathrm{Coll}$ Cardiol 1993;22:796-804

4 Cannon RO, Dilsizian V, O'Gara PT, Udelson JE, Tucker E, Panza JA, et al. Impact of operative relief of outflow obstruction on thallium perfusion abnormalities in hypertrophic cardiomyopathy. Circulation 1992;85:1039-45.

5 Takata J, Counihan PJ, Gane JN, Yoshinori D, Chikamori $\mathrm{T}$, Ozawa $\mathrm{T}$, et al. Regional thallium-201 washout and 
myocardial hypertrophy in hypertrophic cardiomyopathy and its relation to exertional chest pain. $\mathrm{Am} 7 \mathrm{Cardiol}$ 1993;72:211-8.

6 Cannon RO, Rosing DR, Maron BJ, Leon MB, Bonow RO, Watson RM, et al. Myocardial ischemia in patients with hypertrophic cardiomyopathy: contribution of inadequate vasodilator reserve and elevated left ventricular filling pressures. Circulation 1985;71:234-43.

7 Cannon RO, Dilsizian V, O'Gara PT, Udelson JE, Schenke WH, Quyyumi A, et al. Myocardial metabolic, hemodynamic and electrocardiographic significance of reversible thallium-201 abnormalities in hypertrophic cardiomyopathy. Circulation 1991;83:1660-7.

8 Grover-McKay M, Swaiger M, Krivokapich J, Perloff JK Phelps ME, Schelbert HR. Regional myocardial blood flow and metabolism at rest in mildly symptomatic patients with hypertrophic cardiomyopathy. $f \mathrm{Am}$ Coll Cardiol 1989;13:317-24.

9 Yoshida K, Endo M, Himi T, Kagaya A, Masuda Y, Inagaki $\mathrm{Y}$, et al. Measurement of regional myocardia blood flow in hypertrophic cardiomyopathy: application of the first-pass flow model using $\mathrm{N}-13$ ammonia and PET. Am f Physiol Imaging 1989;4:97-104.

10 Camici P, Chiriatti G, Lorenzoni R, Bellina RC, Gistri R, Italiani G, et al. Coronary vasodilation is impaired in both hypertrophied and nonhypertrophied myocardium of patients with hypertrophic cardiomyopathy: a study with nitrogen-13 ammonia and positron emission tomog raphy. $\mathcal{F}$ Am Coll Cardiol 1991;17:879-86.

11 Nienaber CA, Gambhir SS, Vaghaiwalla Mody F, Ratib O, Huang SC, Phelps ME, et al. Regional myocardial blood flow and glucose utilization in symptomatic patients with flow and glucose utilization in symptomatic patients with hypertrophic

12 Perrone-Filardi P, Bacharach SL, Dilsizian V, Panza JA, Maurea S, Bonow RO. Regional systolic function, myocardial blood flow and glucose uptake at rest in hypertrophic cardiomyopathy. Am $f$ Cardiol 1993;72: 199-204.

13 Blanksma PK, Posma JL, De Jong RM, Pruim J, Willemsen ATM, Anthonio RL, et al. Positron emission tomography characterization of the myocardium in hypertrophic cardiomyopathy. In: Van Der Wall EE, Blanksma PK, Niemeyer MG, Paans AMJ, eds. Cardiac positron emission tomography: viability, perfusion, receptors and cardiomyopathy. Dordrecht, NL: Kluwer Academic Publishers, 1995; thy. Dordr.

14 Slade AKB, Sadoul N, Shapiro L, Chojnowska L, Simon JP, Saumarez RC, et al. DDD pacing in hypertrophic cardiomyopathy:

15 Nishimura RA, Danielson GK. Dual chamber pacing for hypertrophic obstructive cardiomyopathy: has its tim come? Br Heart $\mathcal{F}$ 1993;70:301-3.

16 Kappenberger L, Jeanrenaud X, Aebischer N. Treatment of hypertrophic obstructive cardiomyopathy with pacing. In: Van Der Wall EE, Blanksma PK, Niemeyer MG, Paans AMJ, eds. Cardiac positron emission tomography: viability, perfusion, receptors and cardiomyopathy. Dordrecht, NL: Kluwer Academic Publishers, 1995; 149-55.

17 Fananapazir L, Dilsizian V, Bonow RO. Dual chamber pacing relieves angina and improves myocardial perfusion abnormalities in patients with obstructive hypersion abnormalities in patients with obstructive hypertrophic cardiom

18 Maron BJ, Epstein SE. Hypertrophic cardiomyopathy: a discussion of nomenclature. Am $\mathcal{f}$ Cardiol $1979 ; 43$ $1242-4$.

19 Seidelin PH, Jones GA, Boon NA. Effects of dual-chamber pacing in hypertrophic cardiomyopathy without obstruction (letter). Lancet 1992;340:369.

20 Cannon RO III, Tripodi D, Dilsizian V, Panza JA, Fananapazir L. Results of permanent dual-chamber pacing in symptomatic nonobstructive hypertrophic cardiomyopathy. Am $\mathcal{F}$ Cardiol 1994;73:571-6.
21 Schelbert HR, Phelps ME, Huang SC, MacDonald, NS Hansen H, Selin, et al. Nitrogen-13 ammonia as an indicator of myocardial blood flow. Circulation 1981;63: cator of

22 Bellina CR, Parodi O, Camici P, Salvadori PA, Taddei L, Fusani $L$, et al. Simultaneous in vitro and in vivo validation of nitrogen-13-ammonia for the assessment of regional myocardial blood flow. F Nucl Med 1990;31: 1335-43.

23 Blanksma PK, Willemsen ATM, Meeder JG, de Jong RM Anthonio RL, Pruim J, et al. Quantitative myocardial mapping of perfusion and metabolism using parametric 36:153-8.

24 Meeder JG, Blanksma PK, Crijns HJGM, Anthonio RL Pruim J, Brouwer J, et al. Mechanisms of angina pectoris in syndrome $\mathrm{X}$ assessed by myocardial perfusion dynamics in syndrome $X$ assessed by myocardial perfusion dynamics

25 Delhaas T, Arts T, Prinzen FW, Reneman RS. Relation between regional electrical activation time and subepicardial fiber strain in the canine left ventricle. Pflügers Arch (Eur F Physiol) 1993;423:78-87.

26 Prinzen FW, Augustijn CH, Arts T, Allessie MA, Reneman RS. Redistribution of myocardial fiber strain and blood flow by asynchronous activation. Am $\mathcal{F}$ Physiol 1990 259:H300-8.

27 Lee MA, Dae MW, Langberg JJ, Griffin JC, Chin MC, Finkbeiner WE, et al. Effects of long-term right ventricular apical pacing on left ventricular perfusion, innervation, function and histology. $\mathcal{F ~ A m}$ Coll Cardiol 1994; 24:225-32.

28 Cannon RO, Schenke WH, Maron BJ, Tracy CM, Leon $\mathrm{MB}, \mathrm{Brush} \mathrm{JE}$, et al. Differences in coronary flow and myocardial metabolism at rest and during pacing myocardial metabolism at rest and during pacing between patients with obstructive and patients with nonobstructive hypertro

29 Koga Y, Yamaguchi R, Ogata M, Kihara K, Toshima H. Decreased coronary vasodilatory capacity in hypertrophic cardiomyopathy determined by split-dose thalliumdipyridamole myocardial scintigraphy. $\mathrm{Am} f \mathrm{Cardio}$ 1990;65:1134-9.

30 Memmola C, Iliceto S, Napoli VF, Cavallari D, Santoro G, Rizzon P. Coronary flow dynamics and reserve assessed by transesophageal echocardiography in obstructive hypertrophic cardiomyopathy. Am $\mathcal{f}$ Cardiol 1994;74: hypertrophic

31 Fine DG, Clements IP, Callahan MJ. Myocardial stunning in hypertrophic cardiomyopathy: recovery predicted by single photon emission computed tomographic thallium 201 scintigraphy. I Am Coll Cardiol 1989;13:1415-8.

32 Gistri R, Cecchi F, Choudhury L, Montereggi A, Sorace $\mathrm{O}$, Salvadori PA, et al. Effect of verapamil on absolute myocardial blood flow in hypertrophic cardiomyopathy. Am $\mathcal{F}$ Cardiol 1994;74:363-8.

33 Niemeyer MG, Meeder JG, Kuijper AFM, Blanksma PK van der Wall. Comparison of thallium scintigraphy and positron emission tomography. In: Van Der Wall EE, Blanksma PK, Niemeyer MG, Paans AMJ, eds. Cardiac positron emission tomography: viability, perfusion, receptors and cardiomyopathy. Dordrecht, NL: Kluwer Academic Publishers, 1995;37-50.

34 Posma JL Blanksma PK, van der Wall EE. Redistribution of myocardial perfusion during permanent dual chamber pacing in symptomatic non-obstructive hypertrophic carpacing in symptomatic non-obstructive hypertrophic cardiomyopathy: a quantitative positron

35 Fananapaz. Br Heart f 1996;76:522-4. D, McAreavey D. Long-term results of dual-chamber (DDD) pacing in obstructive hypertrophic cardiomyopathy, evidence for progressive symptomatic and hemodynamic improvement and reduction of left ventricular hypertrophy. Circulation 1994;90:2731-42.

36 Oakley CM. Non-surgical ablation of the ventricular septum for the treatment of hypertrophic cardiomyopathy. Br Heart f 1995; 74:479-80. 